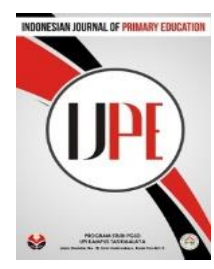

Vol. 2, No. 2 (2018) 23-27 ISSN: 2597-4866

Indonesian Journal of Primary Education

\title{
Assessment Pembelajaran IPS SD Kelas V
}

\author{
Selia Wahyu Kaeksi \\ Universitas Negeri Yogyakarta \\ *Corresponding author: Selia.wahyu2016@student.uny.ac.id
}

Diterima 20 Agustus 2018; Direview 18 September 2018; Diterima 15 Oktober 2018

Diterbitkan online 28 Desember 2018

\begin{abstract}
This research is intended to find out the implementation of social studies assessment and obstacles that is endeavored by grade $V$ teacher in Bintang Bintang Element in the implementation of IPS learning assessment. Using descriptive research with qualitative approach. The subjects of this research are seven teachers of grade $V$ in elementary school Bintang. Data completion techniques use: 1) observation, 2) interviews, and 3) documentation. Data analysis using interactive model analysis techniques Miles and Huberman the steps are data reduction, data display, and conclusion drawing. Researchers use triangulation techniques to analyze the information that produces. Implementation of gradeV IPS learning assessment by teachers at SD Gugus Bintang is good enough because it covers three aspects of cognitive, affective, and psychomotor. But there are some schools that have not yet been assessed. The obstacles felt by grade V teachers in the Star Cluster in mengassessment IPS learning are: 1) Cognitive, teachers do not use the rubric of assessment for essay problems, and teachers have not found a way to improve the ability to memorize students. 2) Affective, not yet a list of lists to analyze each student's progress. 3) Psychomotoric, teachers do not use assessment rubrics to judge the images students make. For grade V teachers in SD Gugus Bintang must pay more attention to indicators in the realm of cognitive, affective, and psychomotor domains in mengassessment IPS learning. It should also further optimize the use of learning media available in each school.
\end{abstract}

Keywords: Assessment; Learning; IPS; SD; Grade V.

\section{Abstrak}

Penelitian ini bertujuan untuk mengetahui pelaksanaan assessment pembelajaran IPS dan hambatan-hambatan yang dihadapi oleh guru kelas V di SD gugus Bintang dalam melaksanakan assessment pembelajaran IPS. Menggunakan penelitian deskriptif dengan pendekatan kualitatif. Subjek penelitian ini adalah tujuh guru kelas V di SD gugus Bintang. Teknik pengumpulan data menggunakan: 1) observasi, 2) wawancara, dan 3) dokumentasi. Analisis data menggunakan teknik analisis model interaktif Miles dan Huberman langkah-langkahnya yaitu reduksi data, display data, danpenarikan kesimpulan. Peneliti penggunakan triangulasi teknik untuk menganalisis informasi yang diperoleh. Pelaksanaan assessment pembelajaran IPS kelas V oleh guru di SD Gugus Bintang sudah cukup baik karena mencakup tiga aspek kognitif, afektif, dan psikomotor. Tapi ada beberapa sekolah yang belum melaksanakan assessment yang meliputi tiga aspek. Hambatan-hambatan yang dirasakan oleh guru-guru kelas $\mathrm{V}$ di Gugus Bintang dalam mengassessment pembelajaran IPS yaitu: 1) Kognitif, guru tidak menggunakan rubrik penilaian untuk menilai soal esai, dan guru belum menemukan cara untuk meningkatkan kemampuan menghafal siswa. 2) Afektif, belum menggunakan daftar checklist untuk mengassessment perkembangan masing-masing siswa. 3) Psikomotorik, guru tidak menggunakan rubrik penilaian untuk menilai gambar yang siswa buat. Bagi guru kelas V di SD Gugus Bintang harus lebih memperhatikan indikatorindikator yang terdapat pada ranah kognitif, ranah afektif, dan ranah psikomotorik dalam mengassessment pembelajaran IPS. Selain itu juga harus lebih mengoptimalkan penggunaan media pembelajaran yang tersedia di sekolah masingmasing.

Kata Kunci: Assessment; Pembelajaran; IPS; SD; Kelas V.

\section{PENDAHULUAN}

Proses pembelajaran merupakan salah satu unsur penting untuk mencapai keberhasilan dalam pembelajaran. Dalam proses pembelajaran itulah terjadi proses transformasi ilmu pengetahuan serta nilai- nilai. Oleh karena itu, pendidikan bukan lagi memberikan stimulus akan tetapi usaha mengembangkan potensi yang dimiliki. Pengetahuan itu tidak diberikan, akan tetapi dibangun oleh siswa (Sanjaya, 2006: 102). 
Siswa SD perlu pembelajaran yang bersifat aktif untuk dapat mengenali dan mengembangkan potensi dalam proses pembelajaran. Dengan demikian, siswa memiliki kesempatan yang luas untuk mengembangkan kemampuannya dalam aspek kognitif, afektif, dan psikomotorik seperti mengemukakan pendapat, berpikir kritis, menyampaikan ide atau gagasan dan sebagainya. Oleh karena itu, seorang guru harus mengetahui kebutuhan dan kemampuan siswa serta memposisikan siswa sebagai subjek belajar, agar dalam proses pembelajaran dapat membuat siswa aktif secara individu dalam memahami materi pelajaran, bekerjasama dan bersosialisasi.

Kenyataannya, karena keterbatasan fasilitas elektronik, guru cenderung menyampaikan materi pelajaran hanya dengan teks book, sebenarnya guru dapat menyajikan materi IPS yang banyak bersifat hafalan menjadi konkrit dalam proses pembelajaran, misalnya dengan melakukan observasi, memanfaatkan sumber daya yang ada di lingkungan untuk kelangsungan proses pembelajaran, dan lain-lain. Selama pembelajaran IPS berlangsung, guru hanya menekankan penilaian pada ranah kognitif saja, sedangkan ranah afektif masih kurang diamati dan dinilai oleh guru. Hal terebut terlihat pada observasi awal yang dilakukan di kelas V di SD Gugus Bintang. Masih ada guru-guru yang dominan dalam pembelajaran (teacher centre) dan belum mempraktikan model-model pembelajaran yang inovatif untuk menggali potensi yang dimiliki siswa.

Adapun penelitian yang pernah dilakukan sebelumnya dan relevan dengan penelitian ini yaitu mengenai evaluasi kinerja kepala sekolah dalam satu gugus yang dilakukan oleh Diah Prabawati pada tahun 2017. Hasilnya menunjukan bahwa kinerja kepala sekolah perlu dilakukan dengan lebih detail dan teliti di sesuai dengan pedoman kinerja. Sedangkan di gugus bintang ini guru sebagai subjek penelitian dan akan melakukan pengamatan yang lebih mendalam agar didapatkan data tentang pelaksanaan assessment pembelajaran IPS oleh guru.

Hasil pengamatan yang dilakukan, menggambarkan bahwa siswa lebih senang mengerjakan tugas daripada mendengarkan penjelasan guru mengenai materi pelajaran IPS. Dari pernyataan guru kelas V di SD Gugus Bintang, siswa diberi soal hanya bersumber dari buku teks saja, guru jarang membuat soal sendiri. Sedangkan soal yang bersumber dari buku teks biasanya hanya berupa soal objektif, isian singkat, dan esay, padahal ada bermacam-macam bentuk soal evaluasi yang sebenarnya bisa guru buat sendiri sesuai dengan materi pembelajaran.

Penilaian (assessment) berhubungan erat dengan setiap bagian dari kegiatan belajar mengajar. Ini menunjukan bahwa proses penilaian tidak hanya menyangkut hasil belajar saja, tetapi juga menyangkut semua proses belajar dan mengajar (Mimin Haryati, 
2007:15). Berdasarkan hasil wawancara dengan Kepala Sekolah dan guru kelas V di SD Gugus Bintang, beliau mengatakan bahwa pelaksanaan penilaian pembelajaran IPS di SD Gugus Bintang kurang maksimal karena biasanya hanya mencakup aspek kognitif. Untuk mendapatkan hasil penelitian yang mendalam, penelitian ini hanya difokuskan pada masalah yang berkaitan langsung dengan pelaksanaan assessment pembelajaran IPS dan untuk mengetahui pelaksanaannya di kelas V.

Pentingnya penilaian dalam kegiatan pembelajaran merupakan hal yang tak terbantahkan. Dari serangkaian kegiatan belajar mengajar yang dilakukan guru dan siswa, penilaian merupakan salah satu kegiatan yang harus dilakukan guna mengetahui sejauh mana siswa memahami materi pelajaran. Maka dari itu, penelitian ini akan mengungkapkan bagaimana assessment pembelajaran IPS kelas V.

\section{METODE PENELITIAN}

Penelitian ini menggunakan penelitian kualitatif yang bersifat deskriptif. Sudarwan Danim, (2010:51) penelitian kualitatif bersifat deskriptif, yaitu data yang terkumpul berbentuk kata-kata, gambar bukan angkaangka. Kalaupun ada angka-angka, sifatnya hanya sebagai penunjang.

Penelitian ini dilaksanakan di SD gugus bintang. Subjek penelitian yang telah tercermin dalam fokus penelitian ditentukan secara sengaja. Subjek penelitian ini menjadi informan yang akan memberikan berbagai informasi yang diperlukan selama proses penelitian. Pada penelitian ini, peneliti mengambil subyek utama penelitian yaitu guru kelas V di SD Gugus Bintang

Tabel 1 Daftar SD Gugus Bintang

\begin{tabular}{ll}
\hline No. & \multicolumn{1}{c}{ Nama Sekolah } \\
\hline 1. & SDN Mawar 1 \\
\hline 2. & SDN Mawar 2 \\
\hline 3. & SDN Rose \\
\hline 4. & SDN Melati 1 \\
\hline 5. & SDN Melati 2 \\
\hline 6. & SDN Jasmine \\
\hline 7. & SDN Indah \\
\hline
\end{tabular}

Observasi dan wawancara digunakan sebagai teknik pengumpulan data. Pada penelitian ini guna menguji keabsahan data, triangulasi sumber dan teknik, diskusi dengan teman sejawat, dan bahan referensi digunakan untuk menguji kredibilitas. Triangulasi sumber digunakan untuk menguji kredibilitas data yaitu dengan cara mengecek data yang telah diperoleh melalui beberapa sumber. Triangulasi teknik dilakukan dengan mengecek data kepada sumber yang sama dengan teknik berbeda. Informasi peneliti dapat dari guru kemudian triangulasi dengan dokumentasi berupa soal evaluasi.

\section{HASIL DAN PEMBAHASAN}

Berdasarkan hasil observasi, wawancara, dan dokumentasi, dalam pembelajaran IPS kelas V oleh guru di SD Gugus Bintang sudah melakukan assessment yang mencakup tiga ranah yaitu ranah kognitif, afektif, dan psikomotorik. Tapi guru kelas $\mathrm{V}$ belum mengassessment beberapa indikator. 
Tabel 2

Tabel Pelaksanaan Assessment

\begin{tabular}{|c|c|c|c|c|}
\hline No & Nama SD & \multicolumn{3}{|c|}{ Aspek } \\
\hline & & Kognitif & Afektif & Psikomotor \\
\hline 1 & $\begin{array}{l}\text { SDN } \\
\text { Mawar } 1\end{array}$ & $\sqrt{ }$ & $\sqrt{ }$ & $\sqrt{ }$ \\
\hline 2 & $\begin{array}{l}\text { SDN } \\
\text { Mawar } 2\end{array}$ & $\sqrt{ }$ & - & $\sqrt{ }$ \\
\hline 3 & SDN Rose & & - & \\
\hline 4 & $\begin{array}{l}\text { SDN } \\
\text { Melati 1 }\end{array}$ & $\sqrt{ }$ & $\sqrt{ }$ & $\sqrt{ }$ \\
\hline 5 & $\begin{array}{l}\text { SDN } \\
\text { Melati } 2\end{array}$ & - & $\sqrt{ }$ & $\sqrt{ }$ \\
\hline 6 & $\begin{array}{l}\text { SDN } \\
\text { Jasmine }\end{array}$ & $\sqrt{ }$ & $\sqrt{ }$ & $\sqrt{ }$ \\
\hline 7 & $\begin{array}{l}\text { SDN } \\
\text { Indah }\end{array}$ & - & $\sqrt{ }$ & $\sqrt{ }$ \\
\hline
\end{tabular}

Tiga SD sudah melaksanakan assessment dengan cukup baik karena sudah mencakup tiga ranah, dan empat SD belum mengassessment pembelajaran IPS dengan baik karena ada beberapa indikator yang belum diassessment. Ada tiga SD yang sudah melaksanakan assessment pembelajaran pada tiga aspek yaitu aspek kognitif, aspek afektif, dan aspek psikomotorik yaitu: SDN Mawar 1, SDN Melati 1, dan SDN Jasmine. Ada dua SD yang belum melaksanakan assessment aspek kognitif yaitu SDN Melati 2 dan SDN Indah. Sedangkan SD yang belum melaksanakan assessment aspek afektif ada dua SD yaitu SDN Mawar 2 dan SDN Rose.

Menurut Davies, Jarolimek dan Foster (Dimyati dan Mudjiono, 2006:201-207) mengatakan bahwa, ranah tujuan pendidikan berdasarkan hasil belajar siswa secara umum dapat diklasifikasikan menjadi tiga, yakni: ranah kognitif, afektif, dan psikomotorik. Indikator dalam assessment pembelajaran adalah untuk mengukur ketiga ranah tersebut. Jadi, guru dapat dikatakan telah melaksanakan assessment pebelajaran dengan baik apabila dalam proses assessment pembelajaran sudah mencakup tiga indikator assessment pembelajaran tersebut. Jadi, pelaksanaan assessment pembelajaran IPS di SD gugus bintang perlu menggunakan panduan yang tepat agar assessment berjalan sesuai dengan ketentuan yang ada.

\section{SIMPULAN}

Pelaksanaan assessment pembelajaran IPS kelas V oleh guru di SD Gugus Bintang sudah cukup baik karena mencakup tiga aspek kognitif, afektif, dan psikomotor. Tapi ada beberapa sekolah yang belum melaksanakan assessment yang meliputi tiga aspek. Ada dua SD yang belum melaksanakan assessment aspek kognitif yaitu SDN Melati 2 dan SDN Indah. Sedangkan SD yang belum melaksanakan assessment aspek afektif ada dua SD yaitu SDN Mawar 2 dan SDN Rose.

Sedangkan hambatan-hambatan yang dirasakan oleh guru-guru kelas V di Gugus Bintang dalam mengassessment pembelajaran IPS yaitu:

\section{Kognitif}

Di SDN Melati 1, SDN Melati 2, SDN Rose, dan SDN Indah, untuk menilai soal esai guru tidak menggunakan rubrik penilaian. Dan di SDN Indah guru belum menemukan cara untuk meningkatkan kemampuan menghafal siswa.

\section{Afektif}

Semua SD di Gugus Bintang untuk mengassessment perkembangan masing- 
masing siswa belum menggunakan daftar checklist.

\section{Psikomotorik}

SDN Mawar 2, SDN Melati 1, SDN Jasmine, SDN Rose, dan SDN Indah, guru tidak menggunakan rubrik penilaian untuk menilai gambar yang siswa buat.

Penelitian tentang assessment pembelajaran IPS ini memiliki kekurangan, sumber data masih terbatas karena hanya mendapat informasi dari guru saja. Instrument yang digunakan juga kurang dapat menggali informasi lebih dalam. Bagi guru kelas V di SD Gugus Bintang harus lebih memperhatikan indikator-indikator yang terdapat pada ranah kognitif, ranah afektif, dan ranah psikomotorik dalam mengassessment pembelajaran IPS. Selain itu juga harus lebih mengoptimalkan penggunaan media pembelajaran yang tersedia di sekolah masing-masing. Guru juga harus mulai belajar menggunakan daftar checklist untuk memantau perkembangan siswa, dan menggunakan rubrik penilaian untuk menilai hasil belajar siswa. Dengan adanya penelitian ini, dapat dijadikan pertimbangan oleh kepala sekolah dalam meningkatkan kegiatan supervise kepada guru agar melakukan assessment sesuai dengan ketentuan.

\section{DAFTAR PUSTAKA}

Wina Sanjaya. (2006). Strategi Pembelajaran. Bandung: PT Fajar Interpratama.

Mimin Haryati. (2007). Model dan Teknik Penilaian Pada Tingkat Satuan Pendidikan.Jakarta: Gaung Persada Press.
Sudarwan Danim. 2010. Profesional dan Etika Profesi Guru. Bandung: Alfabeta.

Dimyati dan Mudjiono. (2006). Belajar dan Pembelajaran.Jakarta: PT. Rineka Cipta.

Diah, P. (2017). Evaluasi Kinerja Kepala Sekolah Taman Kanak-Kanak SeGugus Ii Argomulyo. (Skripsi). Program Studi Pendidikan Guru Pendidikan Anak Usia Dini, Fakultas Ilmu Pendidikan, Universitas Negeri Yogyakarta. 